\title{
ANTECEDENTS AND CONSEQUENCES OF KNOWLEDGE INTEGRATION IN PRODUCT DEVELOPMENT. AN EMPIRICAL EVIDENCE
}

\section{IE Business School Working Paper WP08-13 05-03-2008}

Elena Revilla

IE Business School

C/María de Molina 12, $5^{\circ}$

28006 Madrid, Spain

elena.revilla@ie.edu

Phone: +34915689600

Fax: +34915610930

(Corresponding author)
Tatiana Cury

\author{
IE Business School \\ C/María de Molina 12, $5^{\circ}$ \\ 28006 Madrid, Spain
}

\begin{abstract}
The purpose of this paper is to explain product development performance through the link between knowledge management and knowledge integration. When product development teams integrate knowledge about two external entities -customers and suppliers, they acquire a better understanding of the market and of each other's needs and capabilities, which enables them to operate and innovate better than their competitors. In this context, our theoretical framework focuses on the social enablers usually associated to knowledge management, and combine them with knowledge integration as to determine product development performance. This performance is measured through two distinct components, or types of outcomes: (1) process outcomes, which analyze the effectiveness of the product development process and it is measured in terms of teamwork- and (2) product outcomes, which concerns the characteristics associated with the value of the product to customer. A survey conducted with product development managers was used in order to develop and test our hypothesis that knowledge integration in combination with knowledge management has a positive impact on product development performance.
\end{abstract}

\section{Keywords}

Knowledge Integration, Product Development, Knowledge Management, trust, learning culture 



\section{INTRODUCTION}

Over the last few decades, corporate emphasis on knowledge has stemmed from pressures such as shortened lead times, intense price pressure, mass customization, and the growth of technological advances. The literature suggests that knowledge and knowledge-based capabilities are necessary elements not only to be managed, but to be stimulated in an environment with increased global competitiveness and highly dynamic markets (Mohrman et al, 2003). Product development is an information -and knowledge- intensive work (Clark and Fujimoto, 1991). Its role within organisations is to create new knowledge or recombine existing knowledge, developing new products and, in this way providing a competitive advantage to the firm. In these circumstances, the development of a steady stream of new products is seen as the only way to ensure survival and success (Mallick and Schroeder, 2005).

Developing highly successful new products is possible through the integration of abilities of both upstream (e.g. design engineers) and downstream knowledge workers (e.g. market experts) (Hong et al.,2005). In spite of significant progress in the use of integrative techniques such as multifunctional teams, concurrent engineering, design for manufacturing and quality function deployment lately, complete integration of all functions involved in product development remains a major management challenge (Mallick and Schroeder, 2005; Koufteros et al, 2005). In many cases, firms discover that their efforts to enhance product development performance fail, not necessarily because of lack of coordination or workflow disruptions, but because of a lack of cross-functional or inter-specialty knowledge about problem constraints (Hoopes and Postrel, 1999).

In a broad sense, one of the major barriers in achieving such integration among all functions involved in product development is the way firms integrate knowledge. Integration has to occur on a conceptual level - beyond operational work (Hong et al, 2005). That means that the members who are involved in the sharing process should be able to interpret the same meaning on the data or information as the other member. In other words, this means that team members should share the same mental model, what will avoid misinterpretation, and repetition of data or information. This suggests the need for a crossfunctional knowledge integration perspective as a key aspect of knowledge-based capabilities. From a management perspective, a central challenge to the success of product development activities is how to integrate and coordinate the specialized knowledge.

The activities associated to the efforts of improving knowledge based capabilities, such as knowledge integration, are identified as knowledge management (Adams, et al, 1998; Becker and Zirpoli, 2003). Knowledge management requires the introduction of criteria to decide which knowledge is most critical for the organization and governance of the factors and conditions that guide the activities of knowledge creation, integration and use (DiBella and Nevis, 1998). Thus, knowledge integration is guided by knowledge management activities, which will, in turn, foster knowledge based capabilities, and therefore, product development performance.

Although, empirical studies of product development have supported the importance of organizational integration for competitive advantage by correlating integrating practices and superior performance (Ettlie, 1995; Moffat, 1998), it is not clear how knowledge integration can actually enhance performance outcomes in product development processes. 
Likewise, there are only a limited number of publications that have begun to examine the way in which knowledge-based capabilities can be facilitated by knowledge management in product development (Song et al., 2006). These studies have shown the relationship to be complex, which suggests that there is a need to understand in greater depth the specific interplays within product development teams.

While the prevailing interest for knowledge management has long been rooted in a informational view that stresses the control of information-seeking and technical solutions, the knowledge management literature has specially reached the point of acknowledging that social characteristics play a key role in the sharing knowledge which can produce hard-toimitate capabilities (Pan and Scarbrough, 1999). Accordingly, we focus our theoretical background on the social enablers usually associated to knowledge management, and combine them with knowledge based capabilities as determining to product development performance. Although KM literature is not precise about these social factors, this study focuses on how two social-organizational knowledge enablers -trust and learning cultureinfluence on knowledge-based capabilities implicit in product development. Specifically, we describe product development performance in terms of the achieving of competence relating to technology (process outcomes) and relating to customers (product outcomes).

The purpose of this paper is double: (1): to examine how product development performance is achieved through knowledge integration and, (2) to explore the facilitating conditions relating to knowledge management that enhance the level of knowledge integration in product development. In order to do this, we first describe the role of knowledge integration capability in the context of product development, and then we explain our research model linking knowledge integration to knowledge management and performance in product development. The third section describes the research methodology used to test the proposed model and hypotheses. The fourth section presents the data analysis and results obtained, while the last section includes the discussion of the findings, the limitations, and further research suggestions.

\section{THEORETICAL FOUNDATIONS AND HYPOTHESES}

\subsection{Knowledge integration capability in the product development}

Shared knowledge is one of the unique, valuable, and critical resources to be developed in order to have competitive advantage (Nonaka y Takeuchi, 1995; Prahalad and Hamel, 1990). Product development is often mentioned as one way to integrate dispersed knowledge of different natures in an innovative manner (Henderson and Cockburn, 1994; Grant, 1996) and to generate new effective knowledge (Iansiti and Clark, 1994) to improve operational competences. On a product development level, teams share knowledge of individuals in order to solve problems and find innovative solutions, creating products that have value in the marketplace (Mohrman et al, 2003).

In a conceptual view, people involved in product development will bring to the product development process their formal and articulated expertise, with their different background, which has been socially constructed along time by particular professional or academic communities. While working in product development, their knowledge will frame their attention when they approach a problem. In this way, they will have the opportunity to 
apply their knowledge to problem resolution and generate new knowledge, both tacit and explicit (Nonaka, et al., 2000).

Accordingly, product development requires a high degree of members' involvement in problem recognition and problem solving processes. In the first step, members must scan, notice and develop meaning for environmental changes. The recognition of the existence of a problem occurs when some stimuli indicate the need for new actions. These stimuli then lead to the second step, when members jointly experience new work processes, tasks, technological characteristics etc. to solve the problem. Product development thus refines the understanding of the environment and improves the ability to react appropriately to future stimulus through knowledge integration.

The need for knowledge integration compels members of the product development team to establish close relationships via language and thought in order to integrate and coordinate their knowledge. Therefore, product development members need to spend considerable time together discussing, reflecting upon their experiences, observing how their colleagues solve tasks, interacting with technologies, and explaining and giving sense to their own actions. Through interaction with others, each member's specialized knowledge is disclosed, shared and legitimized in order to become a part of the product development process. Therefore, the product development process requires the integration of specialized and diverse individual perspectives during problem recognition and problem solving processes. In other words, during the product development, cross-functional work brings together a variety of specialists who share and integrate their knowledge on customer needs, market segments, firm capabilities, competitor strategies and so on, in order to design and develop a specific product (Clark and Fujimoto, 1991).

In this study, we look at the primary purpose of product development as integrating knowledge about mainly two external entities - customers and suppliers. Shared knowledge of customers increases the understanding of the changing customer' needs and value-tocustomer attributes (Slater and Narver, 1994). Shared knowledge of suppliers allows product development to better understand suppliers' design, process, and manufacturing capabilities and enhance customer value because a substantial portion of their final product depends on suppliers' work.

Thus, this paper provides an appropriate level of analysis for examining the influence of knowledge management on knowledge integration capability, and the resulting product development output.

\subsection{Social knowledge management enabler}

Knowledge integration capability in product development depends on how involved individuals are able to share and organize their specific knowledge competences effectively, and also on how they use their distinctive knowledge synergistically to produce a collaborative, ongoing learning. Researchers and practitioners strive for clues on how to appropriately manage knowledge resources in order to create an organizational context where members of the product development process may work attending to different information, assigning new meanings, and trying new approaches when making sense of technical problems. 
The idea of KM management has come to the fore in the business literature due to the increased awareness of the importance of knowledge for organization's prosperity and survival. In particular, the "knowledge-based view of the firm" proposes knowledge as a key firm resource and a source of competitive advantage (Grant, 1996; Kogut and Zander, 1992). KM refers to identifying, developing and leveraging knowledge in organizations to help them to compete (Alavi and Leidner, 2001). Broadly speaking, it encompasses any initiative concerned with the creation, acquisition, capture, sharing and use of knowledge, skills, and expertise, whether these are explicitly labelled as KM or not (Pan and Scarbrough, 1999).

The development of KM in theory and practice involves a wide range of contributions, each bringing their respective experiences, beliefs, and practices. Contemporary KM approaches often reflect the strong division between those interested in the "technology side", and those emphasizing the "human side" of KM (Alvesson and Karreman, 2001; Gloet and Berrell, 2003). It seems noticeable that although IT may inspire KM, it cannot deliver it alone. IT cannot provide a full understanding of complex situations. It is just a portion of what is possible and necessary for effective KM. Knowledge is usually developed by individuals on the basis of day-to-day collective work and, as such, knowledge is a continuous result of interactions between people, within and outside the organization. Social enablers are thus accepted as a real pipeline to create a context that is a medium to guide and motivate people towards knowledge related activities. It derives from the practices, principles, norms and values that underpin the behaviour of an organization and its members, and is usually cultivated over along period. The advantages of this knowledge management orientation as a critical success factor for learning and knowledge development in organizations have been widely recognized in literature (Gold et al., 2001; Lee and Choi, 2003; Zarraga and Bonache, 2003; Chuang, 2004).

In this paper, we deliberately neglect the technological part of the KM discourse to focus on its social dimension. From this point of view, knowledge management initiatives should be consciously and deliberately concerned with providing conditions such that people can trust each other, work together, are motivated to share ideas, and can engage in dialogues. These behaviours are expected to affect the individuals' capacities to integrate knowledge, skills, and expertise as they work. Thus, the existing knowledge management literature is open to explanations where it is possible to discern the role of the organizational culture (shared values) and climate for learning (Gold et al., 2001; Lee and Choi, 2003; Van der Brink, 2003; Chuang, 2004) and other social aspects as important to implementing a successful knowledge management program.

We position ourselves in this social perspective, and thus in the management of people, cultural values, and structural influences in order to handle the problem of managing knowledge in product development. Specifically, we select two major elements as significant in making up knowledge integration capability in product development: trust and learning culture.

Trust involves the maintaining of reciprocal faith in each other in terms of intentions and behaviours. Some scholars define trust as one party's confidence in its partner's reliability and integrity (Morgan and Hunt, 1994). Team members, who trust each other, are more willing to share relevant ideas and comprehensive information, clarify problems and share 
long-term goals. In this same line, Dyer (1997) suggests that trust is required to maximize the use of knowledge in effective collaboration. As such, team members tend to be more wiling to participate in knowledge exchange and creation (Lee and Choi, 2003).

The information, know-how, and capabilities shared at work can be valuable assets that could be used asymmetrically to gain advantages for some team members (Eisenhardt, 1989). When trust is embedded in the relationship among team members, opportunistic behaviour is unlikely to occur because product development members ignore short-term individual gains in favour of the long-term interest of product development. Trust-based interchanges rely on mutual interest between team members (Dwyer et. al, 1987). Trust allows assessing whether team members will act in the common interest and not jeopardize the product development. It is an important restraint to opportunistic behaviour (Morgan and Hunt, 1994).

In the light of these considerations, we expect trust to facilitate knowledge integration. We establish our first hypothesis as follows:

Hypotheses 1: Trust positively influences knowledge integration capability in product development

Learning culture involves the existence of a collective conviction of the importance of knowledge and learning, which supports the routine of communicating and achieving a common language and methodology at work (Dougherty et al., 2004). Effective knowledge sharing occurs in companies that are characterized by greater openness and access to information and resources at all levels. Interaction, dialogue, and frequent contacts must be promoted in a learning culture in order to create new ideas, share them, transmit tacit knowledge, and facilitate solutions to novel or existing problems. Learning culture gives support to innovation. Organizational cultures with several controls and little freedom and risk-tolerance can inhibit creativity and innovation (McLean, 2005) which are sources of success in product development.

One major reason for failure in product development is the attitude of protecting individual functions rather than securing participation across functions. A participative learning culture incentives processes to gain firsthand knowledge from other team members (Song et. al, 1998).However, the different backgrounds of each member can often produce friction or conflicts that erode trust. Thus, a culture properly channelled to the learning and collaborative relationships should focus on the communalities among members rather than their differences.

Several authors have found that a learning culture is one of the critical success factors for achieving knowledge integration within team and give a fast responsiveness to markets (Hodgetts et al, 1999). Thus, we establish our second hypothesis as follows:

Hypotheses 2: Learning culture influences knowledge integration capability in product development

\subsection{Product development performance}

Just knowing that product development may vary in its levels of knowledge integration is not particularly compelling. What makes this of particular interest is that these differences in 
knowledge integration capability may significantly and differentially affect product development performance.

Knowledge is at origin of most improvements in customer value (Andersen and Narus, 1998). Its contribution to performance is result of renewing and improving operational competences. Therefore, the organization must use the shared knowledge through product development to provide more valuable products to its customers, and making it harder for them to switch to another supplier. In doing so, organizations need to know about customer's needs and foster products that are superior in solving problems for users. It implies using shared knowledge to sense and act upon trends in the market and generate new strategic opportunities. As result, firms try to do more and better than rivals and to come up with ways to offer customers lower prices or superior quality.

Craven (1998) recognize that the responsibility for creating and delivering superior value does not lie within a firm across different functional departments. Not only customers can be a source of information, but also suppliers linked to the product development process share the responsibility in problem recognition and problem solving. Thus, in order to guarantee better performance and to maximize the fit with customer needs, product development must also take into account the supplier's competences. Successful product developments are those that can find the match between their new developments goals and their suppliers' resources and competences (Schilling and Hill, 1998). The matching of complex customer requirements to suppliers engineering and manufacturing capabilities is fundamental in the generation of customer value. Collaboration and coordination is greatly facilitated when product development integrates common knowledge of both customer requirements and suppliers capabilities.

In view of this, the outcomes of product development are classified in two categories: (1) process outcomes, which analyze the effectiveness of the product development process in term of teamwork and (2) product outcomes concern the characteristics associated with product and its value to customer.

Teamwork refers the degree of collaborative behaviour in the product development team (Zirger and Maidique, 1990, Hong, 2005) and the effectiveness of developing new products from product concept to manufacturing. When cooperation and shared knowledge for integrated problem solving exists, the members of product development get work done quickly, cost and engineering hours are reduced and members have a general sense of productivity and timely conflict resolution, creative problem solving, and effective decision implementation and communication. Based on this explanation the following hypothesis is proposed:

Hypotheses 3: Knowledge integration capability positively influences in process outcomes measured in term of teamwork.

Value to customer express the value of the new product in meeting the customer needs and expectations in the market place (Clark and Fujimoto, 1991). It is also reflected in the product success in the market place and its creation of value to customer in terms of highly perceived product quality (Clark and Wheelright, 1995). At this respect, product development with good capacities for knowledge integration is likely to be more adept at continually revamping knowledge and overcome competence traps and rigidities (Leonard,1992) by facilitating the sensing and seizing of market and technological 
opportunities. Iansity and Clark (1994) empirically showed that the ability to integrate knowledge resources influences product quality. Likewise, it has been found that knowledge integration is most strongly related to superior product quality, an antecedent of superior customer value (Slater and Narver, 1994). Thus, given the potential of knowledge integration capability on product outcomes, we set the following fourth hypothesis:

Hypotheses 4: Knowledge integration capability positively influences in product outcomes measured in term of value to customer.

\section{RESEARCH METHODOLOGY}

\subsection{Sample characteristics and data collection}

Survey methodology has been used for the empirical analysis. The questionnaire has been designed and developed from a thorough literature review, and simplified by us in some indicators. The questionnaire was next validated through a pre-test carried out through several personal interviews with product development executives. These interviews allowed us to purify our survey items and rectify any potential deficiency. Minor adjustments were made on the basis of specific suggestions.

After the pilot study, the mailing list was obtained from Madri $+\mathrm{d}^{1}$. Respondents were product development managers, selected according to a representative population, and contacted by telephone or mail. Those who agreed to participate in the study received the questionnaire by e-mail or by a web page access where the questionnaire was available. They had to answer to questions having in mind a single specific product development process. The sample characteristics were not significantly different from the corresponding population parameters of the original sample provided by Madri $+\mathrm{d}$. As a result, 79 products development managers provided responses. In terms of industry type, we covered a wide number of industries. Table 1 summarizes respondent characteristics in terms of total number of employees.

Table 1. Respondents by firm's size

\begin{tabular}{cc}
\hline \multicolumn{2}{c}{ Firms by size } \\
\hline Up to 499 & $65,80 \%$ \\
$500-999$ & $9,60 \%$ \\
$1000-4999$ & $12,30 \%$ \\
$5000-9999$ & $6,80 \%$ \\
over 10.000 & $5,50 \%$ \\
\hline
\end{tabular}

Since the original questionnaire was a larger one, we only chose the questions that helped investigate the hypotheses detailed in this research. In this particular piece of research, questions on knowledge integration (from customers and suppliers), social enablers (trust and learning culture) and process and product outcomes were used.

\footnotetext{
${ }^{1}$ Madrid is a society that groups firms and public research organizations aimed of improving of competitiveness through encouraging research, development, innovation and knowledge transfer.
} 


\subsection{Measures description}

The measurement of the analysis variables has been built on a multiple-items method, which enhances confidence about the accuracy and consistency of the assessment. Each item was based on a five point Likert scale and all of them are perceptual variables. Table 2 displays items used to measure the analysis variables.

Table 2. Description of measurement items for each construct

\begin{tabular}{|c|c|c|c|c|}
\hline \multicolumn{2}{|r|}{ Construct } & Measurement items & Mean & S.D. \\
\hline \multirow{6}{*}{ 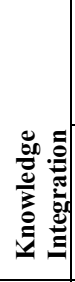 } & \multirow{3}{*}{$\begin{array}{l}\text { Customer } \\
\text { Knowledge } \\
\text { (SKCUST) } \\
\end{array}$} & (a1h) How well we were doing on customer satisfaction ratings. & 3,68 & 0,938 \\
\hline & & (a2d) Which features were most valued by target customers. & 3,86 & 0,924 \\
\hline & & (a2k) Current customer needs. & 3,99 & 0,934 \\
\hline & \multirow{3}{*}{$\begin{array}{l}\text { Supplier } \\
\text { knowledge } \\
\text { (SKSUPPL) }\end{array}$} & (a2c) Our suppliers' design capabilities. & 3,44 & 0,979 \\
\hline & & (a2j) Our suppliers' capabilities to meet time requirements. & 3,65 & 0,969 \\
\hline & & (a3a) Our suppliers' capabilities to meet quality requirements. & 3,70 & 0,933 \\
\hline \multirow{6}{*}{ 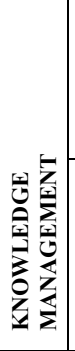 } & \multirow{3}{*}{$\begin{array}{l}\text { Trust } \\
\text { (TRUST) }\end{array}$} & (fa9) Project members are generally trustworthy & 4,23 & 0,733 \\
\hline & & $\begin{array}{l}\text { (fa10) Project members are respectful and understandable to what other } \\
\text { members need while they are doing their job. }\end{array}$ & 3,82 & 0,675 \\
\hline & & $\begin{array}{l}\text { (fa11) Project members have reciprocal faith in other's abilities, intentions and } \\
\text { behaviours. }\end{array}$ & 4,10 & 0,691 \\
\hline & \multirow{3}{*}{$\begin{array}{l}\text { Learning } \\
\text { culture } \\
\text { (LEARNC) }\end{array}$} & $\begin{array}{l}\text { (fa1) Projects managers consider failures as an opportunity to learn instead a } \\
\text { reason to be ashamed of. }\end{array}$ & 4,10 & 0,761 \\
\hline & & $\begin{array}{l}\text { (fb1) Projects managers clearly support the role of knowledge in the firm's } \\
\text { success. }\end{array}$ & 3,95 & 0,766 \\
\hline & & $\begin{array}{l}\text { (fb3)Projects managers make efforts to improve the employees' knowledge and } \\
\text { skills. }\end{array}$ & 3,87 & 0,925 \\
\hline \multirow{7}{*}{ 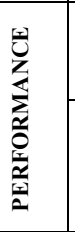 } & \multirow{3}{*}{$\begin{array}{l}\text { Value to } \\
\text { customer } \\
\text { (VALUECUST) }\end{array}$} & (c2a) The product had a high quality. & 4,09 & 0,724 \\
\hline & & (c2c) The product exceeded customer expectations. & 3,68 & 0.904 \\
\hline & & (c2k) The product created a high customer value. & 3,97 & 0,805 \\
\hline & \multirow{4}{*}{$\begin{array}{l}\text { Teamwork } \\
\text { (TEAMWORK) }\end{array}$} & (c1d)Team was productive & 3,91 & 0,747 \\
\hline & & (c1h) Team members coordinated their activity well & 3,82 & 0,818 \\
\hline & & (c11) Team used product engineering hours effectively & 3,63 & 0,870 \\
\hline & & (c1m) Team members implemented decisions effectively & 3,95 & 0,737 \\
\hline
\end{tabular}

Knowledge integration capability. Knowledge integration construct was represented by two variables: shared knowledge of customers (skcust) and shared knowledge of providers (sksuppl). Following Hong et al (2004), there were 6 items that measured knowledge integration: three for knowledge of customer (Customer satisfaction ratings, features most valued by target customers and current customer needs) and three for knowledge of supplier (suppliers' process and design capabilities, time requirements and quality requirements).

Social knowledge management enablers have been measured with 6 items corresponding to trust and learning culture as indicated in Table 2. Trust refers to level to which the project members are considered trustworthy, sincere, respectfull and have relationships based on reciprocal faith. Learning culture values the importance and the role of knowledge in the firm's success, the efforts to improve the employees' knowledge and the consideration of failures as learning opportunities. Most of these items have been adapted from Lee and Choi (2003), Gold et al. (2001), Thomset and Hoest (2001) and Zarraga and Bonache (2003). 
Product development performance was measured through two components: Teamwork values process outcomes and value to customer expresses product outcomes. Specially, to capture process outcome, we ask product development managers to indicate the extent to which the product development team worked well together, coordinated activities well, implemented decisions effectively, was productive, and used product engineering hours efficiently. These items were previously used by Hong et al. (2004) who drawn them from Alder (1995), Ali et al. (1995), Crawford (1992) and Tersine and Hummingbird, (1995). To capture value to customer we ask our respondents to indicate in a five point Likert scale, the degree to which the product had a high quality, exceeded customer expectations, created a high customer value (Hong, 2000).

This study developed valid and reliable scales to measure the variables at use, which are essential for testing the model in Figure 1. The process was based on commonly accepted methods for developing standardized instruments (Churchill, 1979; Nunnally, 1978). An extensive literature review ensured that the research model is grounded in theory. In addition, case studies and structured interviews with product development executives helped to define the domain of the constructs and facilitate item generation.

\section{ANALYSIS AND RESULTS}

\subsection{Psychometric proprieties of measurement scales}

Before testing this model, a series of tests was performed to asses the unidimensionality of the measures. Because multiple-item construct measures variables, and to verify that items tapped into their stipulated construct, a confirmatory factorial analysis (CFA) was employed to determine the validity of the constructs.

Table 3 summarizes the number of items and the results of the reliability and validity test for the analysis variables. The internal consistency measures (Cronbach's alpha) were obtained in order to assess the reliability of the measurement instruments. All but the Cronbach alpha for Learning Culture are above acceptable levels. Three separate confirmatory factor analysis were conducted by using SPSS 12: one corresponding to each of the social enablers (constructs of trust and learning culture), one for the dimensions of knowledge integration (customer knowledge and supplier knowledge) and one more for product development performance (teamwork and value to customer). Based on these statistics and theoretical considerations we deleted items if appropriate (Anderson and Gerbing, 1988). Convergent validity was established by confirming that all scale items loaded significantly on their hypothesized constructs factors (Anderson and Gerbing, 1988). Discriminant validity was assessed by comparing the $\chi^{2}$ differences between a constrained CFA (where the interfactor correlation was set to 1 , indicating they are the same construct) and an unconstrained model (where the interfactor correlation was free). All $\chi^{2}$ differences were found to be significant, providing support for discriminant validity (Anderson and Gerbing, 1988).

We have previously defined knowledge integration as a higher order construct composed of customer knowledge and supplier knowledge. To confirm the multidimensionality of the knowledge integration as a higher-order construct we ran a second-order CFA. Table 3 
shows how the loadings of the measurement items on the first-order factors, and the loadings of the measurement items of he first-order factors (knowledge stocks and learning flows) on the second-order factor (knowledge integration) were all significant ( $\leq \leq 0.05$ ). This second-order CFA was estimated by resuming in single factors the indicators of the customer knowledge construct and the supplier knowledge construct through principal components analysis (using SPSS 12.0 for Windows).

Table 3. Results of reliability and validity for the measures

\begin{tabular}{|c|c|c|c|}
\hline Paths & $\begin{array}{c}\text { Standardized } \\
\text { loadings }\end{array}$ & $\begin{array}{l}\text { Goodness of } \\
\text { fit indices }\end{array}$ & $\begin{array}{c}\text { Reliability } \\
\text { (Cronbach } \alpha)\end{array}$ \\
\hline $\begin{array}{l}\text { First order } \\
\text { Customer Knowledge(SKCUST) } \\
\text { A1H } \\
\text { A2D } \\
\text { A2K } \\
\text { Supplier Knowledge (SKSUPPL) } \\
\text { A2C } \\
\text { A2J } \\
\text { A3A }\end{array}$ & $\begin{array}{c}0,891 \\
0,847 \\
0,827 \\
\\
0,902 \\
0,901 \\
0.806\end{array}$ & $\begin{array}{c}\text { Chi square }= \\
3,605 \\
(\mathrm{P}=0.462) \\
\mathrm{Df}=4\end{array}$ & 0,907 \\
\hline $\begin{array}{l}\text { First order } \\
\text { Value to Customer (VALUCUST) } \\
\text { C2A } \\
\text { C2C } \\
\text { C2K } \\
\text { Teamwork (TEAMWORK) } \\
\text { C1D } \\
\text { C1H } \\
\text { C1L } \\
\text { C1M }\end{array}$ & $\begin{array}{c}0.603 \\
0,738 \\
0,788 \\
\\
0,701 \\
0,678 \\
0,820 \\
0,888\end{array}$ & $\begin{array}{c}\text { Chi square }= \\
8,584 \\
(\mathrm{P}=0.379) \\
\mathrm{Df}=8\end{array}$ & 0,779 \\
\hline $\begin{array}{l}\text { First order } \\
\text { Trust (TRUST) } \\
\text { FA9 } \\
\text { FA10 } \\
\text { FA11 } \\
\\
\text { Learning Culture (LEARNC) } \\
\text { FA1 } \\
\text { FB1 } \\
\text { FB3 }\end{array}$ & $\begin{array}{c}0,798 \\
0,712 \\
0,851 \\
\\
0,641 \\
0,592 \\
0,632\end{array}$ & $\begin{array}{c}\text { Chi square }= \\
1,482 \\
(\mathrm{P}=0.830) \\
\mathrm{Df}=4\end{array}$ & 0,824 \\
\hline $\begin{array}{l}\text { Second order } \\
\text { Knowledge integration } \\
\text { Skcust } \\
\text { Sksuppl }\end{array}$ & $\begin{array}{l}0,715 \\
0,703\end{array}$ & & 0,743 \\
\hline
\end{tabular}

\subsection{Results of path analysis}

We use a structural equation model (conducted with MPlus) to determine the significant paths between trust, learning culture and knowledge integration, and between the last and teawork and value to customer. A measurement model of four correlated first-order factors 
is examined, and also a construct of second order for the Knowledge Integration was built using the factors SKSUPPL and SKCUST.

Results are shown in Figure 1, which illustrates the estimated path coefficients and their associated t-values (in parenthesis) as well as the goodness of fit indices (which proves a good overall fit for the model).

\section{Figure 1}

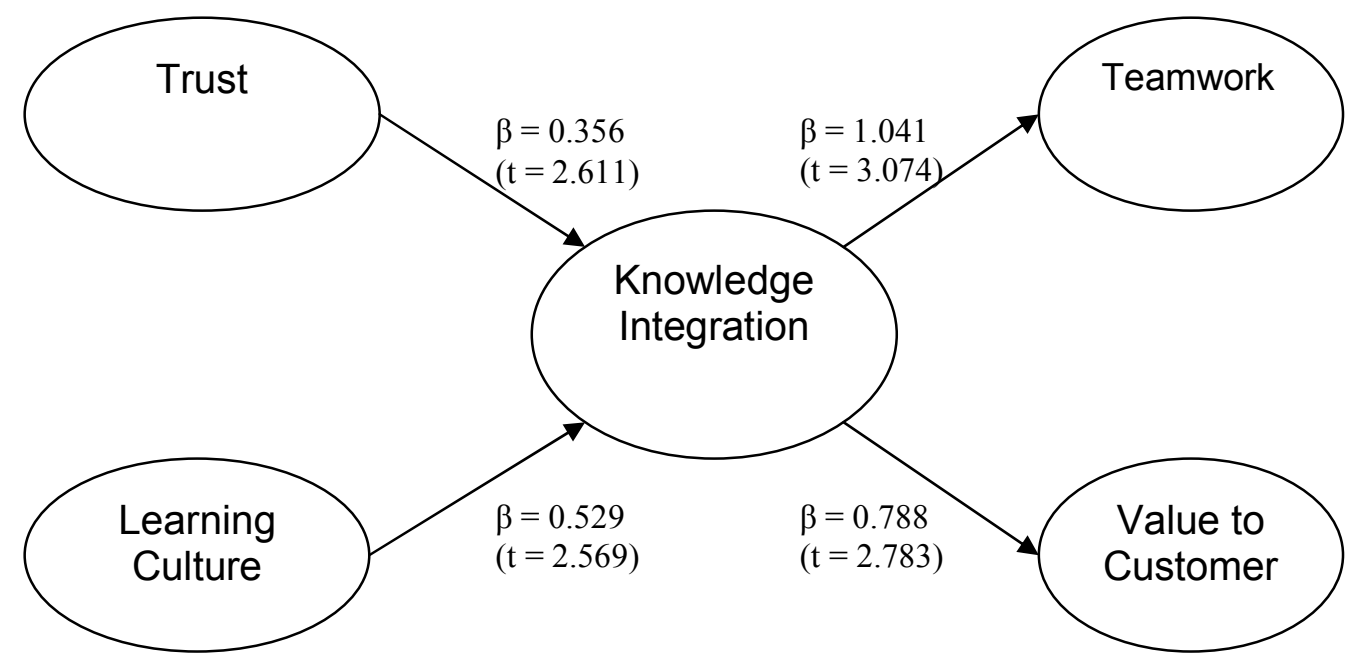

All proposed paths are significant. First, the path coefficient from trust to knowledge integration loaded 0,356, which supports the existence of a significant link $(\mathrm{t}=2.611$, $\mathrm{p}<0.05)$ as stated in our hypothesis 1 . For the second hypothesis, the path between Learning Culture and Knowledge integration is also significant $(0,529$ and $t=2.569)$, also supporting our hypothesis.

For the third and fourth hypotheses, that knowledge integration has a positive effect on both process and product outcomes, measured through teamwork and value to customer, the results also show support, and the paths are also positive and significant $(1,041$ and 0,788 respectively, with $\mathrm{t}=3.074$ and 2,783 ).

The model has good model-data fit $\left(\chi^{2}=155.722,144\right.$ degrees of freedom, $p$-value of 0.2383 ., RMSEA $=0.033$, TLI $=0.980, \mathrm{CFI}=0.983$ ). The completely standardized coefficients (item-factor loadings) of the resulting model ranged from 0.464 to 0.771 . The coefficients and their associated $t$-values are all statistically significant at $p<0.05$. No problems are revealed among the residuals in the fitted residuals matrix (Hu and Bentler, 1995). 


\section{DISCUSSION AND LIMITATIONS}

The purpose of this paper was to develop and test a framework that examines how product development performance (teamwork, value to customer) is achieved through the integration of knowledge about two external entities -customer and suppliers- and to explain the facilitating conditions that enhance the level of knowledge integration in product development, under a social knowledge management perspective (trust and learning culture). Our results support all of the hypotheses and show how the link between knowledge management and knowledge integration capability explain product development performance. These findings fill the gap and contribute to the understanding of the way in which knowledge-based capabilities can be facilitated by knowledge management and its role in product development.

Clearly, customers and suppliers knowledge integration has a significant effect on product development performance. Higher levels of knowledge base capabilities lead to higher levels of performance. This finding about the effect of knowledge integration replicates and extends research by Hong et al. (2005) who find a positive relationship between knowledge sharing and firm performance in product development.

Thus, customer knowledge integration appears to be vital for product innovation. Customers can provide access to information about the changing customer needs and value to customer attribute. Its integration and understanding within product development can result in products that better meet customer expectations and higher capability levels in introducing new products in the marketplace. Likewise, suppliers possess valuable information and expertise about materials, pricing, technology, designs, timing, etc. which can be invaluable in the product development process. The integration and understanding of these information can also enhance product development performance because a substantial portion of final product depends on suppliers' work.

This research finds that trust has a positive effect on knowledge integration. According to the mainstream thinking, this finding states that trust is a facilitator of effective cooperative behaviour in customer and suppliers relationships (Dwyer, et al., 1987) in product development. The benefits of trust and its role to alleviate some of the risks and dilemmas associated with knowledge integration were supported by this study.

This study also shows that learning culture influence knowledge integration. An organization committed to learning seeks a full understanding of its environment, including customers and suppliers. This suggest that product development itself is a learning process that enable the implementation of new ideas and the integration of knowledge of individuals to solve problems and find innovative solutions to create product that have value in the marketplace. Through a learning culture, individuals learn and develop new skills as well as share existing knowledge, both of which are crucial for product development. The literature has long acknowledged the benefits that a learning culture has in firms that aspire to stand out through product development (Calantone et al, 2002).

The findings of this research about the positive effect of trust and learning culture on knowledge integration encourage researchers in management to apply a knowledge base view into applied fields such as product development. For that reason, it is not surprising 
that, knowledge management is increasingly regarded as prerequisite for creating successful and innovative organizations (Cardinal and Hatfield, 2000)

Our results must be viewed in the light of the study's limitations. First, the sample size is not large. As a second limitation, it is necessary say that we have tried to define our constructs as precisely as possible by drawing on relevant literature and to closely link our measures to the theoretical underpinnings through a careful process of item generation and refinement. Evidently, this measurement effort represents an advance for research but, nonetheless, our research items are far for being perfect as long as they measure facts that are neither fully nor easily measurable. Another limitation concerns the fact that all data was collected from the same respondent using the same perceptual measurement technique. Although our findings may help to explain certain relationships between variables, we are aware that replies from multiple respondents would have ruled out potential drawbacks. We should also have in mind that both the external environment (i.e. customers' characteristics) and the organization's internal characteristics (i.e. the context of product development) naturally interferes with product development efforts, therefore amplifying or attenuating the organization's tendency to explore and/or exploit. This work is thus obviously only a preliminary step towards a better understanding of the impact of social knowledge management approach in knowledge integration in product development and, on the basis of previous limitations it naturally points out avenues for future research. 


\section{REFERENCES}

Adams, M.E., Day, G.S. and Dougherty, D. (1998). "Enhancing New Product Development Performance: An Organizational Learning Perspective”. Journal of Product Innovation Management, 15:403-422.

Adler, P.S., Goldoftas, B., Levine, D.I. (1999). "Flexibility Versus Efficiency? A Case Study of Model Changeovers in the Toyota Production System”. Organization Science, 10 (1): 43-68.

Alavi, M. and Leidner, D.E. (2001). "Review: Knowledge Management and Knowledge Management Systems: Conceptual Foundations and Research Issues”. MIS Quarterly, 25 (1): 107-136.

Ali, A., Krapfel, R., Jr. ,LaBahn, D.,(1995). "Product Innovativeness and entry strategy: Impact on cycle time and break-even time”. Journal of Product Innovation Management 12 (1): 54-69.

Alvesson, M. and Karreman, D. (2001). “Odd Couple: Making Sense of the Curious Concept of Knowledge Management”. Journal of Management Studies, 38 (7): 995-1018.

Becker, M.C. and Zirpoli, F. (2003). “Organizing New Product Development. Knowledge Hollowing-Out and Knowledge Integration-The Fiat Auto Case". International Journal of Operation \& Production Management, 23 (9): 1033-1061.

Chuang, S. (2004). "A Resource-Based Perspective on Knowledge Management Capability and Competitive Advantage: An Empirical Investigation”. Expert Systems with Applications, 27: 459-465.

Clark, K. B., and Fujimoto, T. (1991). "Product development performance: Strategy, organization, and management in the world auto industry". Boston, MA: Harvard Business School.

Crawford, C.M. (1992). "The hidden cost of accelerated product development". Journal of Product Innovation Management 9 (3): 188-199.

Dwyer, R., Schurr, P., \& Oh. S. (1987). “Developing buyer-seller relationship”. Journal of Marketing, 51(4): 11-27.

Dyer, J.H. (1997). "Effective inter-firm collaboration: How firms minimize transaction cost and maximize transaction value". Strategic Management Journal, 18(7): 535-556.

Eisenhardt, K. (1989). "Agency Theory: an assessment and a review". Academy of Management Review, 14:57-74.

Gloet, M. and Berrel, M. (2003). "The dual Paradigm Nature of Knowledge Management: Implications for Achieving Quality Outcomes in Human Resource Management”. Journal of Knowledge Management, 7 (1): 78-89.

Gold, A.H., Malhotra, A. and Segars, A.H. (2001). "Knowledge Management: An Organizational Capabilities Perspective”. Journal of Management Information Systems, 18 (1): 185-214.

Grant, R. (1996). “Toward a Knowledge-Based Theory of the Firm”. Strategic Management Journal, 17 (Winter special Issue): 199-122.

Henderson, R. and Cockburn, I. (1994). “Measuring Competence? Exploring Firm Effects in Pharmaceutical research". Strategic Management Journal, 15(special issue): 63-84.

Hodgetts, R. M., Luthans, F., \& Slocum, J. W. (1999). "Strategy and HRM initiatives for the '00s environment: Redefining roles and boundaries, linking competencies and resources". Organizational Dynamics, 28(2): 7-21.

Hong, P (2000). “Knowledge Integration in Integrated Product Development”. Doctoral Thesis. University of Toledo, USA

Hong, P., Doll, W. J, Nahm, A. And Li, X. (2004). "Knowledge sharing in integrated product development". European journal of innovation management, 7, 2:102-112

Hong, P., Vonderembse, M., Doll, W. J, \& Nahm, A. (2005). "Role Changes of Design Engineers in Integrated Product Development”. Journal of Operations Management, 24(1): 63-79.

Hoopes, D.G. and Postrel, S. (1999). "Shared Knowledge, "Glitches", and Product Development Performance”. Strategic Management Journal, 20: 837-865. 
Iansiti, M. and Clark, K.B. (1994). "Integration and Dynamic Capability: Evidence from Product Development in Automobiles and Mainframe Computers". Industrial and Corporate Change, 3(3): 557605.

Kogut, B. and Zander, U. (1992). 'Knowledge of the Firm, Combinative Capabilities, and the Replication of Technology'. Organization Science, 383-397.

Koufteros, X and Vonderemse, M. and Jayaram, J. (2005). "Internal and External Integration for Product Development: The Contingency Effects of Uncertainty, Equivocality and Platform Strategy". Decision Science, 36, (1): 97-133.

Lee, H. and Choi, B. (2003). "Knowledge Management Enablers, Processes, and Organizational Performance: An Integrative View and Empirical Examination”. Journal of Management Information Systems, 20 (1): 179-228.

Leonard Barton, D. (1995). "Wellsprings of Knowledge. Building and Sustaining the Sources of Innovation”. Harvard Business Scholl Press, Boston, MA, USA.

Mallic, D.M. and Schroeder, R.G. (2005). “An integrated Framework for Measuring Product Development Performance in High Technology Industries". Production and Operations Management; 4, (2): 142-158.

McLean, L.D. (2005). "Organizational culture's influence on creativity and innovation: A review of the literature and implications for human resource development". Advances in Developing Human Resources, 7 (2): 226-246.

Mohrman, S.A. and Finegold, D. and Mohrman, A.M (2003): "An Empirical Model of the Organization Knowledge System in New Product Development Firms". Journal of Engineering and Technology Management, 20: 7-38.

Morgan, R.M., \& Hunt, S.D. (1994). “The commitment-trust theory of relationship marketing”. Journal of Marketing, 58: 20-38

Nonaka, I. and Takeuchi, H. (1995). The Knowledge Creating Company. Oxford University Press, New York.

Nonaka, I., Toyama, R. and Nagata, A. (2000). "A Firm as a Knowledge-Creating Entity: A New Perspective on the Theory of the Firm”. Industrial and Corporate Change, 9 (1): 1-20.

Pan, S.L. and Scarbrough, H. (1999). "Knowledge Management in Practice: An Exploratory Case Study". Technology Analysis \& Strategic Management, 11 (3): 359-374.

Prahalad, C.K. and Hamel, G. (1990). “The core competence of corporation”. Harvard Business Review, 68 (3): 79-91.

Slater, S.F. and Narver, J.C. (1994). "Does competitive environment moderate the market-orientationperformance relationship?", Journal of Marketing, 58:46-57

Song, X. M., Thieme, J. R., \& Xie, J. (1998). "The impact of cross-functional joint involvement across product development stages: An exploratory study". Journal of Product Innovation Management, 15(4): 289-304.

Tersine, R.J., Hummingbird, E.A. (1995). "Lead-time reduction the search for competitive advantage". International Journal of Operations and Production Management 12 (2):8-18.

Van den Brink, P. (2003). "Social, Organizational and Technological Conditions that Enable Knowledge Sharing". Doctoral thesis, Technische Universiteit Delft, Amsterdam.

Zárraga, C. and Bonache, J. (2003). "Assessing the Team Environment for Knowledge Sharing: An Emprirical Analysis”. International Journal of Human Resource Management, 14 (7): 1227-1245. 
NOTAS

בx


NOTAS

בx


NOTAS 